Pacific Journal of Mathematic 


\title{
NORMAL STRUCTURE COEFFICIENTS FOR BANACH SPACES
}

\author{
W. L. BYNUM
}

\begin{abstract}
This paper introduces several geometric concepts in Banach spaces related to normal structure and uses these ideas to generalize a recent theorem of Baillon for fixed points of nonexpansive mappings.
\end{abstract}

1. Definitions. The concepts introduced in this paper are phrased in terms of reflexive Banach spaces. This is not a serious restriction, but rather one of technical convenience. All of the concepts discussed here deal with closed bounded convex subsets of a reflexive Banach space, so one could replace "closed bounded and convex" with "weakly compact and convex", if desired.

For the following definitions, $X$ will denote a reflexive Banach space and $C$ will denote a closed bounded convex subset of $X$.

For each $x$ in $C$, let $r(x, C)=\sup \{\|x-y\|: y$ in $C\}$ and let $R(C)$ denote the Čebyšev radius of $C[11$, p. 178]:

$$
R(C)=\min \{r(x, C): x \text { in } C\} .
$$

This minimum is achieved because of the weak compactness of $C$. Let $D(C)$ denote the diameter of $C, D(C)=\sup \{\|x-y\|: x, y$ in $C\}$.

A space $X$ has normal structure [2] provided that for each closed bounded convex subset $C$ of $X$ with more than one member, $R(C)<D(C)$.

The three Banach space coefficients defined in the following paragraphs are the principal objects of study in this paper.

The normal structure coefficient of $X$, denoted by $N(X)$, is the infimum of the set of number $D(C) / R(C)$ taken over all closed convex subsets $C$ of $X$ with more than one member.

The asymptotic diameter of a bounded sequence $\left\{x_{n}\right\}$ in $X$ is defined to be $\lim _{n} \sup \left\{\left\|x_{m}-x_{k}\right\|: m \geqq n, k \geqq n\right\}$. The bounded sequence coefficient of $X$, denoted $B S(X)$, is the supremum of the set of all numbers $M$ with the property that for each bounded sequence $\left\{x_{n}\right\}$ with asymptotic diameter $A$, there is some $y$ in the closed convex hull of the sequence such that $M \cdot \lim \sup _{n}\left\|x_{n}-y\right\| \leqq A$.

The weakly convergent sequence coefficient of $X$, denoted by $W C S(X)$, is defined similarly, replacing "bounded" with "weakly convergent".

These three coefficients are related to normal structure in that if any one of the three is greater than 1 (all are between 1 and 2), the space has normal structure; this result is established in $\S 2$. An 
example is given at the end of $\S 2$ of a space with normal structure for which all three coefficients are 1, so the converse of the previous statement is false.

The primary focus of this paper is on the coefficient $\operatorname{WCS}(X)$ for two reasons. First, because of Theorem 1 below, it appears to be the "weakest" of the three coefficients, and second, it seems to be the easiest of the three to evaluate, at least for the $l_{p}$ spaces $(1<p<\infty)$ and some of their isomorphs. Intuitively, it seems that the three coefficients should be equal, at least for some limited class of spaces. However, J.-B. Baillon has constructed an example of a reflexive Banach space $X$ such that $N(X)=1$ and $W C S(X)=2^{1 / 2}$ (see $\S 2$ ).

The paper is organized as follows. Section 2 contains basic theorems and several examples, $\S 3$ contains a theorem relating the coefficients to the Banach-Mazur distance coefficient, and $\S 4$ contains a fixed point theorem for nonexpansive mappings.

2. Examples and basic results. The three coefficients are related by the following theorem.

Theorem 1. For a reflexive Banach space $X$,

$$
1 \leqq N(X) \leqq B S(X) \leqq W C S(X) \leqq 2 .
$$

Proof. The inequalities $1 \leqq N(X)$ and $B S(X) \leqq W C S(X)$ follow from the definitions, and it is obvious from the triangle inquality that $W C S(X) \leqq 2$.

We shall show that $N(X) \leqq B S(X)$. Take a bounded sequence $\left\{x_{n}\right\}$ in $X$ with asymptotic diameter $A$, and for each $n$ let $C_{n}$ be the closed convex hull of $\left\{x_{n}, x_{n+1}, \cdots\right\}$.

If there is an $n$ such that $C_{n}$ has only one member, then the sequence $\left\{x_{n}\right\}$ is constant from that point on, and if $u$ is that constant, we have $N(X) \lim \sup _{n}\left\|x_{n}-u\right\|=A=0$.

So suppose that each $C_{n}$ has more than one member. The definition of $N(X)$ implies that for each $n N(X) \cdot R\left(C_{n}\right) \leqq D\left(C_{n}\right)$. For each $y$ in $C_{1}$, let $\beta(y)=\lim \sup _{n}\left\|x_{n}-y\right\|$. Since $\beta$ is continuous and convex and since $C_{1}$ is weakly compact, there is some $y_{0}$ in $C_{1}$ at which $\beta$ achieves its minimum value.

For each $n$, there is some $z_{n}$ in $C_{n}$ such that $r\left(z_{n}, C_{n}\right)=R\left(C_{n}\right)$, and for such a point it is clear that

$$
\beta\left(y_{0}\right) \leqq \beta\left(z_{n}\right) \leqq r\left(z_{n}, C_{n}\right) \leqq D\left(C_{n}\right) / N(X) .
$$

But it is easy to show that $D\left(C_{n}\right)=\sup \left\{\left\|x_{m}-x_{k}\right\|: m, k \geqq n\right\}$, so that the sequence $\left\{D\left(C_{n}\right)\right\}$ decreases to $A$. Consequently, $\beta\left(y_{0}\right) \leqq$ 
$A / N(X)$, and $N(X) \leqq B S(X)$, as desired.

For a separable reflexive space $X$, every closed bounded convex subset contains a dense sequence, so in this case, $N(X)=B S(X)$. J.-B. Baillon has noted that if $X$ is taken to be the $l_{2}$-direct sum of the spaces $R_{\infty}^{n}, n \geqq 1$, where $R_{\infty}^{n}$ is the space $R^{n}$ with the maximum norm, then $X$ is separable and reflexive and $N(X)=B S(X)=$ $1<W C S(X)=2^{1 / 2}$, which shows that the coefficients need not be equal.

If any one of these coefficients for a space $X$ is greater than one, then $X$ has normal structure. First, it is obvious from the definitions that $X$ has normal structure if $N(X)>1$. As far as the other two coefficients are concerned, if $X$ lacks normal structure, then by [9, Proposition 3] there is a diametral sequence in the unit ball of $X$ converging weakly to zero with asymptotic diameter one; that is, there is a sequence $\left\{x_{n}\right\}$ in the unit ball of $X$ such that $\left\|x_{n}\right\| \rightarrow 1, x_{n} \rightarrow 0$, and the distance from $x_{n+1}$ to the convex hull of $\left\{x_{1}, \cdots, x_{n}\right\}$ tends to 1 as $n \rightarrow \infty$. This last condition implies that for each $y$ in the convex hull of the sequence, $\lim _{n}\left\|x_{n}-y\right\|=1$, so that $W C S(X)=B S(X)=N(X)=1$. Therefore, if either $B S(X)$ or $W C S(X)$ is greater than 1 , then $X$ has normal structure also.

The fixed point theorem of $\S 4$ is phrased in terms of $W C S(X)$, and fortunately this coefficient seems relatively easy to evaluate for the $l_{p}$ spaces $(1<p<\infty)$.

\section{TheOREM 2. For $1<p<\infty, W C S\left(l_{p}\right)=2^{1 / p}$.}

Proof. Let $\left\{x_{n}\right\}$ be a sequence in $l_{p}$ with asymptotic diameter $A$ converging weakly to a point $z$, and let $B=\lim \sup _{n}\left\|x_{n}-z\right\|$. By choosing a subsequence $\left\{x_{n_{k}}\right\}=\left\{w_{k}\right\}$ such that $\lim _{k}\left\|w_{k}-z\right\|=B$, we obtain that for each $y$ in $l_{p} \lim _{k}\left\|w_{k}-y\right\|^{p}=B^{p}+\|y-z\|^{p}$. If we denote this last quantity by $\beta(y)^{p}$, then $\lim \sup _{n} \beta\left(x_{n}\right) \leqq A$, and $\beta\left(w_{k}\right)^{p}=B^{p}+\left\|w_{k}-z\right\|^{p}$, so that $\lim \sup _{n} \beta\left(x_{n}\right) \geqq 2^{1 / p} B$ and $A \geqq 2^{1 / p} B$. Consequently, $W C S\left(l_{p}\right) \geqq 2^{1 / p}$.

For the opposite inequality, the usual Schauder basis $\left\{e_{n}\right\}$ of $l_{p}$ has asymptotic diameter $2^{1 / p}$ and $\lim _{n}\left\|e_{n}-0\right\|=1$, so $W C S\left(l_{p}\right)=2^{1 / p}$.

Theorem 2.6 of $\left[6\right.$, p. 112] shows that $N\left(l_{2}\right)=2^{1 / 2}$, so that Theorems 1 and 2 above imply that all three constants coincide in the case of $l_{2}$.

Unfortunately, the normal structure coefficients for $L_{p}[0,1]=L_{p}$ seem to be difficult to determine, and no precise values have been obtained. By considering various sequences in $L_{p}$, it is relatively easy to show that $W C S\left(L_{p}\right) \leqq \min \left\{2^{1-1 / p}, 2^{1 / p}\right\}$, so that when $1<p<2$, $W C S\left(L_{p}\right)$ and $W C S\left(l_{p}\right)$ must differ. The bound given above is a likely candidate for the actual value of $W C S\left(L_{p}\right)$, but so far noth- 
ing definite has been obtained.

The question of how these coefficients relate to the modulus of convexity of a space is a natural one to ask, and the following theorem gives a partial answer.

TheOREM 3. If $X$ is a reflexive Banach space with modulus of convexity $\delta$, then $N(X) \geqq(1-\delta(1))^{-1}$.

Proof. Let $C$ be a closed bounded convex subset of $X$ with more than one member, and let $\varepsilon>0$.

Choose $x$ and $y$ in $C$ such that $\|x-y\| \geqq D(C)-\varepsilon$, let $w=$ $(x+y) / 2$, and choose $z$ in $C$ such that $\|z-w\| \geqq r(w, C)-\varepsilon$. Then by the definition of $\delta$

$$
\|z-w\| \leqq D(C)(1-\delta((D(C)-\varepsilon) / D(C)))
$$

and by the definition of $R(C)$

$$
R(C) \leqq r(w, C) \leqq\|z-w\|+\varepsilon .
$$

Combining these two inequalities with the continuity of $\delta[10, p$. 145], we obtain that $R(C) \leqq(1-\delta(1)) D(C)$, from which the desired result follows.

This theorem shows that if $\delta(1)>0$, then $N(X)>1$, and consequently, $X$ has normal structure. This implication was first noted in [8] with essentially the same argument as above.

Note that by Theorem $1, \delta(1)>0$ also implies that both $W C S(X)$ and $B S(X)$ are greater than one. The space $l_{p, 1}$ (defined in [3]), which is simply $l_{p}$ renormed with the norm described below, is an interesting space to consider now, because it is not uniformly convex (its modulus of convexity is zero on the interval $\left[0,2^{1 / p}\right]$ ), yet it has normal structure. Moreover, as we shall see in Theorem 4 below, $W C S\left(l_{p, 1}\right)=2^{1 / p}$.

The norm for $l_{p, 1}$ is defined as follows (see [3]): for $x$ in $l_{p}$ and for each $n$, let $x^{+}(n)=\max \{x(n), 0\}$, and let $x^{-}=(-x)^{+}$. If $\|\cdot\|$ denotes the usual $l_{p}$ norm, then define the norm $|\cdot|$ for $l_{p, 1}$ by $|x|=$ $\left\|x^{+}\right\|+\left\|x^{-}\right\|$.

THEOREM 4. For $1<p<\infty, W C S\left(l_{p, 1}\right)=2^{1 / p}$.

Proof. Without loss of generality, we can consider a sequence $\left\{x_{n}\right\}$ converging weakly to 0 . By choosing as many subsequences as necessary, we can obtain a subsequence $\left\{x_{n_{k}}\right\}=\left\{z_{k}\right\}$ such that $z_{k} \rightarrow 0$, $\left|z_{k}\right| \rightarrow \lim \sup _{n}\left|x_{n}\right|,\left\|z_{k}^{+}\right\| \rightarrow B$, and $\left\|z_{k}^{-}\right\| \rightarrow C$ as $k \rightarrow \infty$.

We shall show that for each $y$ in $l_{p, 1}$, 


$$
\left\|\left(z_{k}-y\right)^{+}\right\|^{p} \longrightarrow B^{p}+\left\|y^{-}\right\|^{p}
$$

and

$$
\left\|\left(z_{k}-y\right)^{-}\right\|^{p} \longrightarrow C^{p}+\left\|y^{+}\right\|^{p} .
$$

Let $\left\{e_{n}\right\}$ denote the usual Schauder basis of $l_{p}$, and for each $x$ in $l_{p, 1}$ and each $m$, let $U_{m} x=x(1) e_{1}+\cdots+x(m) e_{m}$ and $V_{m} x=x-U_{m} x$.

We shall show that (1) holds. Fix $m$ and note that $\left\|U_{m}\left(z_{k}-y\right)^{+}\right\| \rightarrow$ $\left\|U_{m}\left(-y^{+}\right)\right\|=\left\|U_{m} y^{-}\right\|$because $z_{k} \rightarrow 0$ as $k \rightarrow \infty$.

For each $k$,

$$
\left\|z_{k}^{+}\right\|-\left\|U_{m} z_{k}^{+}\right\|-\left\|V_{m} y^{+}\right\| \leqq\left\|V_{m} z_{k}^{+}\right\|-\left\|V_{m} y^{+}\right\| \leqq\left\|V_{m}\left(z_{k}-y\right)^{+}\right\|
$$

and

$$
\left\|V_{m}\left(z_{k}-y\right)^{+}\right\| \leqq\left\|V_{m} z_{k}^{+}\right\|+\left\|V_{m} y^{-}\right\| \leqq\left\|z_{k}^{+}\right\|+\left\|V_{m} y^{-}\right\| .
$$

Because $z_{k} \rightarrow 0$, it follows that $\lim _{k}\left\|U_{m} z_{k}^{+}\right\|=0$, and thus

$$
\lim \inf _{k}\left\|V_{m}\left(z_{k}-y\right)^{+}\right\| \geqq B-\left\|V_{m} y^{+}\right\|
$$

and

$$
\lim \sup _{k}\left\|V_{m}\left(z_{k}-y\right)^{+}\right\| \leqq B+\left\|V_{m} y^{-}\right\| .
$$

Consequently, for each $m$ :

$$
\lim \sup _{k}\left\|\left(z_{k}-y\right)^{+}\right\|^{p} \leqq\left\|U_{m} y^{-}\right\|^{p}+\left(B+\left\|V_{m} y^{-}\right\|\right)^{p}
$$

and

$$
\lim \inf _{k}\left\|\left(z_{k}-y\right)^{+}\right\|^{p} \geqq\left\|U_{m} y^{-}\right\|^{p}+\mid B-\left\|V_{m} y^{+}\right\| \|^{p} .
$$

By taking limits as $m \rightarrow \infty$, we obtain the result sought, namely statement (1) above. The proof of statement (2) is similar.

Consequently, for each fixed $n$,

$$
\lim _{k}\left|z_{k}-x_{n}\right|=\left(B^{p}+\left\|x_{n}^{-}\right\|^{p}\right)^{1 / p}+\left(C^{p}+\| x_{n}^{+}||^{p}\right)^{1 / p} .
$$

Setting $n=n_{k}$ in this expression and letting $k \rightarrow \infty$, we obtain finally that $2\left(B^{p}+C^{p}\right)^{1 / p}$ does not exceed the asymptotic diameter $A$ of the sequence $\left\{x_{n}\right\}$. On the other hand, $\lim \sup _{n}\left|x_{n}-0\right|=$ $B+C$, and by the Hölder inequality, $B+C \leqq 2^{1-1 / p}\left(B^{p}+C^{p}\right)^{1 / p}$. Consequently, $2^{1 / p} \lim \sup _{n}\left|x_{n}-0\right| \leqq A$, and so $W C S\left(l_{p, 1}\right) \geqq 2^{1 / p}$.

To obtain the reverse inequality, let $x_{n}=e_{2 n}-e_{2 n+1}$. The asymptotic diameter of this sequence is $2^{1+1 / p}$ and $\lim _{n}\left|x_{n}-0\right|=2$, so that $W C S\left(l_{p, 1}\right) \leqq 2^{1 / p}$, and at last the proof is complete.

We conclude this section with another example: a space $X$ with normal structure such that $N(X)=B S(X)=W C S(X)=1$.

Let $X$ be the $l_{2}$-direct sum of the sequence of spaces $\left\{l_{n}\right\}_{n \geq 2}$; i.e., 
let $X$ be the collection of all sequences $x=\left\{x_{n}\right\}_{n \geqq 2}$ such that $x_{n}$ is in $l_{n}$ for each $n$ and $|x|^{2}=\Sigma_{n}\left\|x_{n}\right\|^{2}<\infty$. This space is reflexive and is easily shown to be uniformly convex in every direction (cf. [7]), so it has normal structure. On the other hand, $W C S(X) \leqq W C S\left(l_{n}\right)=$ $2^{1 / n}$ for each $n$, so all three constants for this space are 1.

3. The normal structure coefficients and the Banach-Mazur distance coefficient. For isomorphic Banach spaces $X$ and $Y$, the Banach-Mazur distance from $X$ to $Y$, denoted $d(X, Y)$, is defined to be the infimum of $\|U\|\left\|U^{-1}\right\|$ taken over all bicontinuous linear operators $U$ from $X$ onto $Y$.

When any one of the normal structure coefficients is greater than one, this condition is contagious. More precisely, we have the following theorem:

THEOREM 5. If $X$ and $Y$ are isomorphic Banach spaces, then $N(X) \leqq d(X ; Y) N(Y), B S(X) \leqq d(X, Y) B S(Y)$, and $W C S(X) \leqq d(X, Y)$ $W C S(Y)$.

Proof. Each of these inequalities has a similar proof. We shall show here that $N(X) \leqq d(X, Y) N(Y)$.

Let $C$ be a closed bounded convex subset of $Y$ with more than one member. If $U$ is an isomorphism of $Y$ onto $X$, then $U(C)$ is a subset of $X$ with the same properties as those of $C$. It follows easily from the definitions that

$$
\begin{aligned}
R_{Y}(C) & \leqq\left\|U^{-1}\right\| R_{X}(U(C)) \leqq\left\|U^{-1}\right\| D_{X}(U(C)) / N(X) \\
& \leqq\left\|U^{-1}\right\|\|U\| D_{Y}(C) / N(X) .
\end{aligned}
$$

Consequently, $R_{Y}(C) \leqq d(X, Y) D_{Y}(C) / N(X)$, from which the desired result follows.

The following observation is a corollary of Theorem 5: if $X$ is a reflexive Banach space such that $N(X)>1$ and if $Y$ is a Banach space such that $d(X, Y)<N(X)$, then $N(Y)>1$ also. A combination of this observation with Theorems 2 and 3 subsumes the results announced in [5].

The space $l_{p, \infty}$, defined in [3], is interesting with regard to the previous paragraph. The space $l_{p, \infty}$ is simply $l_{p}$ renormed with the norm $|x|=\max \left\{\left\|x^{+}\right\|,\left\|x^{-}\right\|\right\}$(see $\S 2$ ). The space $l_{p, \infty}$ lacks normal structure (see [3]) and $d\left(l_{p, \infty}, l_{p}\right)=2^{1 / p}$, yet by the remark in the previous paragraph if $d\left(l_{p}, Y\right)<2^{1 / p}$, then $Y$ has normal structure, so that the space $l_{p, \infty}$ is a sort of "limiting case" of spaces with normal structure.

This space is also interesting with regard to the concept of asymptotic normal structure introduced in [13]. A Banach space $X$ 
has asymptotic normal structure provided that for each closed bounded subset $C$ of $X$ with more than one member and each sequence $\left\{x_{n}\right\}$ in $C$ with the property that $\lim _{n}\left\|x_{n}-x_{n+1}\right\|=0$, there is some $y$ in $C$ such that $\lim \inf _{n}\left\|x_{n}-y\right\|<D(C)$. The space $l_{p, \infty}$ lacks asymptotic normal structure also (see [4]), and since normal structure implies asymptotic normal structure, the space $l_{p, \infty}$ is a sort of "limiting case" of spaces with asymptotic normal structure as well.

4. A fixed point theorem for nonexpansive mappings. The following theorem is a generalization of a recent fixed point theorem of Baillon [1] (see the Corollary below).

THEOREM 6. If $X$ is a uniformly convex Banach space and if $Y$ is a Banach space such that $d(X, Y) \leqq W C S(X)$, then each nonexpansive selfmap of a closed bounded convex subset of $Y$ has a fixed point.

Proof. Let $C$ be a closed bounded convex subset of $Y$ and let $T$ be a fixed-point-free nonexpansive selfmap of $C$. Let $K$ be a minimal closed convex subset of $C$ which is selfmapped by $T$. Let $\|\cdot\|$ denote the norm on $X$ and $|\cdot|$ the norm on $Y$.

By a result of Karlovitz [12] if $\left\{x_{n}\right\}$ is a sequence in $K$ such that $\lim _{n}\left|x_{n}-T x_{n}\right|=0$, then for each $y$ in $K, \lim _{n}\left|x_{n}-y\right|=$ $D_{Y}(K)=D$. By replacing $\left\{x_{n}\right\}$ with one of its subsequences, we can assume that $\left\{x_{n}\right\}$ converges weakly to some point of $K$.

Choose $0<b<1$. By the definition of $d(X, Y)$ there is an isomorphism $U$ of $Y$ onto $X$ such that $\left\|U^{-1}\right\|=1$ and $b\|U\|<d(X, Y) \leqq$ $W C S(X)$. If $A$ is the asymptotic diameter of $\left\{U x_{n}\right\}$, then since $\left\{U x_{n}\right\}$ converges weakly in $X$ there is some $w$ in $K$ with the property that $U w$ is in the closed hull of $\left\{U x_{n}\right\}$ and $\beta(U w)=\lim \sup _{n}$ $\left\|U x_{n}-U w\right\| \leqq A / W C S(X)$. But for each $n,\left|x_{n}-w\right| \leqq\left\|U x_{n}-U w\right\|$, so by the previous paragraph,

$$
D \leqq \beta(U w) \leqq A / W C S(X)<A /(b\|U\|) .
$$

Since it is easy to show that $A \leqq\|U\| D$, we obtain the following results from (3):

$$
\begin{gathered}
b D\|U\|<A \\
\beta(U w)<D / b .
\end{gathered}
$$

For simplicity in what follows, let $M=D\|U\|$.

By the definition of $A$ and by (4) above, there exist $m$ and $n$ as large as desired such that 


$$
b M<\left\|U x_{m}-U x_{n}\right\| .
$$

Note that $\left\|U x_{m}-U x_{n}\right\| \leqq\|U\|\left|x_{m}-x_{n}\right|$, so that inequality (6) implies that $\left|x_{m}-x_{n}\right|>b D$. Since $\lim _{n}\left|x_{n}-T x_{n}\right|=0$, it follows that $\lim _{n}\left\|U x_{n}-U T x_{n}\right\|=0$ also, and thus we can find $m$ and $n$ as large as desired such that the inequalities $\left|x_{m}-T x_{m}\right|<1-b,\left|x_{n}-T x_{n}\right|<$ $1-b$, and $b M<\left\|U T x_{m}-U T x_{n}\right\|$ hold in addition to inequality (6).

Now if $f=U T x_{m}-U\left(T\left(x_{m}+x_{n}\right) / 2\right)$ and if $g=U\left(T\left(x_{m}+x_{n}\right) / 2\right)-$ $U T x_{n}$, then $\|f\|<M / 2,\|g\|<M / 2$, and by the previous sentence and the uniform convexity of $X$ we obtain:

$$
b M<\|f+g\|<M(1-\delta(2\|f-g\| / M)) .
$$

From this, the strict monotonicity of $\delta$, and the choice of $U$, we obtain finally that:

$$
\begin{aligned}
\left|x_{m}+x_{n}-2 T\left(\left(x_{m}+x_{n}\right) / 2\right)\right| & \leqq\left|x_{m}-T x_{m}\right|+\left|x_{n}-T x_{n}\right|+\|f-g\| \\
& <2(1-b)+(M / 2) \delta^{-1}(1-b) \\
& <2(1-b)+(D / 2 b) d(X, Y) \delta^{-1}(1-b) .
\end{aligned}
$$

Since the right side of the last inequality approaches zero as $b$ approaches one, it follows that there exist subsequences $\left\{x_{m_{k}}\right\}$ and $\left\{x_{n_{k}}\right\}$ with these two properties:

$$
\text { if } \begin{gathered}
z_{k}=\left(x_{m_{k}}+x_{n_{k}}\right) / 2 \text {, then } \lim _{k}\left|z_{k}-T z_{k}\right|=0 . \\
\lim _{k}\left|x_{m_{k}}-x_{n_{k}}\right|=D .
\end{gathered}
$$

Now again choose some $b$ in $(0,1)$, choose an isomorphism $U$ as before and obtain a $w$ in $K$ such that (5) holds; namely, lim $\sup _{n}$ $\left\|U x_{n}-U w\right\|<D / b$.

By Karlovitz's result [12] again, we obtain from (7) that $D=$ $\lim _{k}\left|z_{k}-w\right| \leqq \lim \inf _{k}\left\|U z_{k}-U w\right\|$. But for $k$ sufficiently large, we know that $\left\|U x_{m_{k}}-U w\right\|$ and $\left\|U x_{n_{k}}-U w\right\|$ are both less than $D / b$ because of (5). By the uniform convexity of $X$ once more, we find that

$$
\begin{aligned}
\left\|U z_{k}-U w\right\| & \leqq(D / b)\left(1-\delta\left(b \| U x_{m_{k}}-U x_{n_{k}}|| / D\right)\right) \\
& \leqq(D / b)\left(1-\delta\left(b\left|x_{m_{k}}-x_{n_{k}}\right| / D\right)\right) .
\end{aligned}
$$

By letting $k \rightarrow \infty$ in this inequality, we obtain from (8) and the continuity of $\delta$ that $D \leqq(D / b)(1-\delta(b))$. Since $b$ is arbitrary in $(0,1)$, we obtain the long-sought contradiction: $D \leqq D(1-\delta(1))$. Therefore, $T$ has a fixed point.

The following result is a corollary of Theorems 2 and 6 .

Corollary (Baillon [1]). Let $X$ be a Banach space having 
norms $|\cdot|_{2}$ and $|\cdot|_{\infty}$ such that $\left(X,|\cdot|_{2}\right)$ is a Hilbert space and $|\cdot|_{\infty} \leqq$ $|\cdot|_{2}$. If $\|\cdot\|$ is the norm for $X$ defined by $|\cdot|=\max \left\{|\cdot|_{2}, 2^{1 / 2}|\cdot|_{\infty}\right\}$, then $(X,\|\cdot\|)$ has the nonexpansive fixed point property.

This corollary gives an alternate proof to the result of Karlovitz [12] that the James space has the nonexpansive fixed point property. In this connection, note that $d\left(l_{p, \infty}, l_{p}\right)=2^{1 / p}$, so that Theorems 2 and 6 show that the space $l_{p, \infty}$ described in $\S 3$ has the nonexpansive fixed point property as well. Since this space lacks asymptotic normal structure, the fixed point theorem of [13] does not apply in this case.

Although uniform convexity is used extensively in the proof of Theorem 6, it is not clear whether uniform convexity can be dropped from the hypothesis; that is, this question remains open: if $d(X, Y) \leqq W C S(X)$ and $W C S(X)>1$, does $Y$ have the nonexpansive fixed point property?

The author would like to thank R.E. Bruck for several conversations about some of the topies of this paper and J.-B. Baillon for his helpful comments about the first draft. The author is grateful to Prof. Baillon and the referee for noticing an error in the proof of Theorem 6 .

\section{REFERENCES}

1. J.-B. Baillon, unpublished.

2. M. S. Brodskii and D. P. Mil'man, On the center of a convex set, Dokl. Akad. Nauk. SSSR N.X., 59 (1948), 837-840.

3. W. L. Bynum, A class of spaces lacking normal structure, Compositio Math., 25 (1972), 233-236.

4. —, An example of a reflexive Banach space lacking asymptotic normal structure, submitted.

5. - Normal structure and the Banach-Mazur distance coefficient, Notices Amer. Math. Soc., 25 (1978),

6. L. Danzer, B. Grunbaum, and V. Klee, Helly's theorem and its relatives, Convexity, Proc. Symp. Pure Math., Amer. Math. Soc., 7 (1963), 101-180.

7. M. M. Day, R. C. James, and S. Swaminathan, Normed linear spaces that are uniformly convex in every direction, Canad. J. Math., XXIII (1971), 1051-1059.

8. K. Goebel, Convexity of balls and fixed point theorems for mappings with nonexpansive square, Compositio Math., 22 (1970), 269-274.

9. J. P. Gossez and E. Lami Dozo, Structure normal et base de Schauder, Bull. Acad. Royale Belgique, (5e ser.) 55 (1969), 673-681.

10. V. I. Gurarii, On the differential properties of the modulus of convexity of a Banach space, Mat. Issled,, 2 (1967), 141-148.

11. R. B. Holmes, A course in optimization and best approximation, Lecture Notes in Mathematics, v, 257, Springer-Verlag, Berlin, 1972.

12. L. A. Karlovitz, Existence of fixed points of nonexpansive mappings in a space without normal structure, Pacific J. Math., 66 (1976), 153-159.

13. R. Schöneberg. Asymptotic normal structure and fixed points of nonexpansive mappings, to appear. 
Received February 20, 1979 and in revised form August 28, 1979. Research supported by a Faculty Research Grant of the College of William and Mary.

College of William and Mary

WILLIAMSBURG, VA 23185 


\title{
PACIFIC JOURNAL OF MATHEMATICS
}

\section{EDITORS}

\author{
DoNALD BABBITT (Managing Editor) \\ University of California \\ Los Angeles, CA 90024 \\ HUGo RossI \\ University of Utah \\ Salt Lake City, UT 84112 \\ C. C. MOORE and ANDREW OGG \\ University of California \\ Berkeley, CA 94720
}

J. DugundJI

Department of Mathematics

University of Southern California

Los Angeles, CA 90007

R. FINN and J. Milgram

Stanford University

Stanford, CA 94305

\section{ASSOCIATE EDITORS}
E. F. BeCKenbach
B. H. NeumanN
F. WOLF
K. YoshidA

\section{SUPPORTING INSTITUTIONS}

\author{
UNIVERSITY OF BRITISH COLUMBIA \\ CALIFORNIA INSTITUTE OF TECHNOLOGY \\ UNIVERSITY OF CALIFORNIA \\ MONTANA STATE UNIVERSITY \\ UNIVERSITY OF NEVADA, RENO \\ NEW MEXICO STATE UNIVERSITY \\ OREGON STATE UNIVERSITY \\ UNIVERSITY OF OREGON
}

\author{
UNIVERSITY OF SOUTHERN CALIFORNIA \\ STANFORD UNIVERSITY \\ UNIVERSITY OF HAWAII \\ UNIVERSITY OF TOKYO \\ UNIVERSITY OF UTAH \\ WASHINGTON STATE UNIVERSITY \\ UNIVERSITY OF WASHINGTON
}

The Supporting Institutions listed above contribute to the cost of publication of this Journal, but they are not owners or publishers and have no responsibility for its content or policies.

Mathematical papers intended for publication in the Pacific Journal of Mathematics should be in typed form or offset-reproduced, (not dittoed), double spaced with large margins. Please do not use built up fractions in the text of the manuscript. However, you may use them in the displayed equations. Underline Greek letters in red, German in green, and script in blue. The first paragraph or two must be capable of being used separately as a synopsis of the entire paper. Please propose a heading for the odd numbered pages of less than 35 characters. Manuscripts, in triplicate, may be sent to any one of the editors. Please classify according to the scheme of Math. Reviews, Index to Vol. 39. Supply name and address of author to whom proofs should be sent. All other communications should be addressed to the managing editor, or Elaine Barth, University of California, Los Angeles, California, 90024.

50 reprints to each author are provided free for each article, only if page charges have been substantially paid. Additional copies may be obtained at cost in multiples of 50 .

The Pacific Journal of Mathematics is issued monthly as of January 1966. Regular subscription rate: $\$ 84.00$ a year $(6$ Vols., 12 issues). Special rato: $\$ 42.00$ a year to individual members of supporting institutions.

Subscriptions, orders for numbers issued in the last three calendar years, and changes of address shoud be sent to Pacific Journal of Mathematics, P.O. Box 969, Carmel Valley, CA 93924, U.S.A Old back numbers obtainable from Kraus Periodicals Co., Route 100, Millwood, NY 10546.

\section{PUBLISHED BY PACIFIC JOURNAL OF MATHEMATICS, A NON-PROFIT CORPORATION}

Printed at Kokusai Bunken Insatsusha (International Academic Printing Co., Ltd.). 8-8, 3-chome, Takadanobaba, Shinjuku-ku, Tokyo 160, Japan. 


\section{Pacific Journal of Mathematics}

\section{Vol. 86, No. 2 December, 1980}

Graham Donald Allen, David Alan Legg and Joseph Dinneen Ward, Hermitian

liftings in Orlicz sequence spaces ............................... 379

George Bachman and Alan Sultan, On regular extensions of measures ........ 389

Bruce Alan Barnes, Representations Naimark-related to $*$-representations; a

correction: "When is a representation of a Banach $*$-algebra

Naimark-related to a $*$-representation?" ........................ 397

Earl Robert Berkson, One-parameter semigroups of isometries into $H^{p} \ldots \ldots .403$

M. Brodmann, Piecewise catenarian and going between rings ............ 415

Joe Peter Buhler, A note on tamely ramified polynomials ............... 421

William Lee Bynum, Normal structure coefficients for Banach spaces ........ 427

Lung O. Chung, Biharmonic and polyharmonic principal functions ......... 437

Vladimir Drobot and S. McDonald, Approximation properties of polynomials

with bounded integer coefficients .............................

Giora Dula and Elyahu Katz, Recursion formulas for the homology of

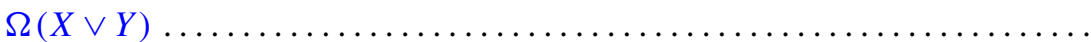

John A. Ernest, The computation of the generalized spectrum of certain Toeplitz operators ...................................... 463

Kenneth R. Goodearl and Thomas Benny Rushing, Direct limit groups and the

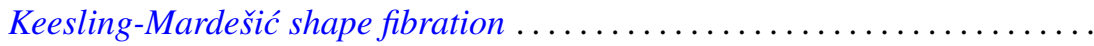

Raymond Heitmann and Stephen Joseph McAdam, Good chains with bad contractions

Patricia Jones and Steve Chong Hong Ligh, Finite hereditary near-ring-semigroups .

Yoshikazu Katayama, Isomorphisms of the Fourier algebras in crossed

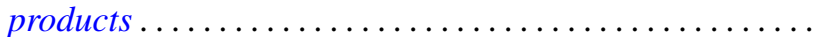

Meir Katchalski and Andrew Chiang-Fung Liu, Symmetric twins and common transversals. .

Mohammad Ahmad Khan, Chain conditions on subgroups of LCA groups ....

Helmut Kröger, Padé approximants on Banach space operator equations ...

Gabriel Michael Miller Obi, An algebraic extension of the Lax-Milgram theorem . .

S. G. Pandit, Differential systems with impulsive perturbation .

Richard Pell, Support point functions and the Loewner variation ...

J. Hyam Rubinstein, Dehn's lemma and handle decompositions of some

4-manifolds

James Eugene Shirey, On the theorem of Helley concerning finite-dimensional subspaces of a dual space.

Oved Shisha, Tchebycheff systems and best partial bases.... 